ORIGINAL RESEARCH ARTICLE

\title{
Changing Patterns of Unmet Needs for Family Planning Among Women of Reproductive Age in Nigeria
}

\author{
Bamgboye E.A and Ajayi I. \\ Department of Epidemiology \& Medical Statistics, Faculty of Public Health, University of Ibadan, Ibadan
}

*For correspondence: Email: dr_enip@yahoo.co.uk; Phone: 08029537711

\begin{abstract}
Unplanned pregnancy poses a major public health challenge to women of reproductive age in Nigeria and this has been hastened by poor use of modern family planning methods. This study employed secondary data analysis of the National HIV/AIDS and Reproductive Health Survey conducted in 2007 and 2012 to explore the the pattern of unmet needs for family planning and associated factors over the five year period. The total unmet needs were 9.1\% in 2007 and increased to $11.4 \%$ in 2012. Identified predictors were locality, fear of side effects and geopolitical zones in both the 2007 and 2012 surveys though with some variations. The level of family planning use among married couples is still very low in Nigeria and there was a rise in the unmet need for family planning among women of reproductive age group over the 5 year period. Regional specific interventions as well as provider-client discussions about family planning can be key to sustained use of modern contraceptives in Nigerian women. (Afr J Reprod Health 2016 (Special Edition); 20[3]: 127-135).
\end{abstract}

Keywords: Unmet Need, Family Planning, Women of Reproductive Age group

\section{Résumé}

La grossesse non planifiée pose un défi majeur de santé publique pour les femmes en âge de procréer au Nigeria et cela a été accéléré par une mauvaise utilisation des méthodes de planification familiale modernes. Cette étude s'est servi d'analyse secondaire des données de l'enquête nationale sur le VIH / SIDA et sur la santé de la reproduction qui a été menée en 2007 et 2012 pour explorer le motif des besoins non satisfaits de planification familiale et les facteurs associés au cours de la période de cinq ans. Les besoins non satisfaits étaient de 9,1\% en 2007 et ont augmenté à 11,4\% en 2012. Les indices identifiés étaient la localité, la peur des effets secondaires et les zones géopolitiques dans les enquêtes de 2007 et 2012 mais avec quelques variations. Le niveau d'utilisation de la planification familiale chez les couples mariés est encore très faible au Nigeria et il y avait une augmentation du besoin non satisfait de planification familiale chez les femmes en âge de procréer au cours de la période de 5 ans. Les interventions spécifiques régionales ainsi que les discussions fournisseur-client sur la planification familiale peuvent être la clé de l'utilisation durable des contraceptifs modernes chez les femmes nigérianes.. (Afr J Reprod Health 2016 (Edition Spéciale); 20[3]: 127-135).

Mots-clés: Besoins non satisfaits, planification familiale, femmes du groupe d'âge de la reproduction

\section{Introduction}

Unplanned pregnancy poses a major public health challenge to women of reproductive age worldwide, especially in developing countries. It has been estimated that about 80 million (38\%) of the 210 million pregnancies that occur annually worldwide, are unplanned, and about 46 million $(22 \%)$ end up in abortion ${ }^{1}$

In developing countries especially in Africa, reproductive health has been a great concern to many stakeholders as access to quality maternal health services is generally poor with significant negative health consequences such as high maternal mortality and morbidity. Family planning has been identified as a way of thinking and living which affects the decisions made by couples in order to promote the health and welfare of family groups. However, the acceptability and voluntary adoption of this practice which affects the health and social development of a country is poor in most developing nations including Nigeria.

Appropriate reproductive health knowledge, belief and confidence of women to accept and access quality family planning services are essential for improvement of reproductive health in women. It is clear that the practice of family planning would have helped individuals or couples to avoid unwanted births, regulate the intervals between pregnancies, control the time at which births occur in relation to the age of parents and determine the number of children in the family 
which would eventually reduce reproductive ill health ${ }^{2}$.

Several strategies have been introduced worldwide to improve access to family planning services, but the unmet needs continue to increase. Unmet need for family planning have been explained as the extent and composition of potential demand for modern family planning methods. Reports have shown a high number of fecund married women who would not like to have children now and like to wait till later but are not using any form of family planning methods ${ }^{4}$. This has been attributed to lack of access to a full range of modern family planning methods, dearth of convincing information on family planning or fear of side effects and therefore these women are unable to meet their reproductive health needs ${ }^{3}$.

The World Health Organization in 2012 highlighted that $12 \%$ of women aged between $15-$ 49 years who were married or in union wanted to avoid pregnancy but had no access to or were not using an effective method of contraceptives ${ }^{4}$. However, many of these women either rely on traditional and less effective methods of contraception or fail to use any method at all due to one barrier or another. These barriers include lack of awareness, lack of access, cultural factors, religious beliefs, opposition to use by partners or family members, and fear of health risks and side effects of contraceptives ${ }^{2,4}$.

As at today, the UN has estimated Nigeria to be 187 million thus urgent steps need to be taken to avoid the danger of over-population with its attendant consequences such as poor living conditions, poor infrastructures and poor health. The findings of 2013 National Demographic Health Survey (NDHS) in Nigeria revealed that about $16 \%$ of married women have a total unmet need for family planning, $12 \%$ have unmet need for spacing and $4 \%$ need to limit family size. These unmet needs signify the gap between the reproductive intentions of couples and their actual contraceptive behaviour and this proportion may just be a tip of the iceberg in the burden of unmet needs for family planning in Nigeria ${ }^{5}$.

Besides, the Total Fertility Rate (TFR) in Nigeria has remained high with a value of 5.5 from the results obtained from the 2013 Nigeria Demographic and Health Survey ${ }^{6}$. One of the major reasons for the high fertility level is the pronatalistic attitude of the population and low use of contraceptive methods thus leading to high rate of unwanted pregnancies, unsafe abortion, abandoned babies, child abuse and ultimately indicating a high percentage of unmet need for family planning ${ }^{5}$. An effective intervention on family planning unmet needs is more likely to facilitate the rapid reduction in the current rates of mortality and morbidity among women of reproductive age in Nigeria.

It has been documented that the cost savings in meeting the Millennium Development Goals (MDGs) by satisfying unmet family planning needs far outweighs the additional cost of investing in other family planning services by a factor of almost three to one ${ }^{3}$. However, in view of the paradigm shift to the post 2015 agenda, a focus on unmet needs of family planning in Nigeria cannot only facilitate reduction in the costs of meeting these needs but can also cause a reduction in maternal deaths by one third thereby contributing to achieving the Sustainable Development Goal three ${ }^{4,7}$.

Several studies have been carried out on the awareness of family planning methods, its usage and factors affecting its use in sub-Saharan Africa including Nigeria, but the studies are limited in scope and geographical coverage. ${ }^{10,14}$ There have been few reports of studies that examined the regional, environmental, socio-cultural differences that may affect the use of the family planning methods and factors associated with unmet need for family planning among women of reproductive age in the different regions of Nigeria. Therefore, this study aimed to explore the changing pattern of unmet need for family planning and associated factors among rural and urban Nigerian women of reproductive age over a five year period using secondary data analysis. The information obtained could reduce the gap in knowledge and practice of family planning methods in Nigeria and inform policy makers in decision making of appropriate health service interventions to promote healthy living especially among women.

\section{Methods}

The data source for this study was from the National HIV/AIDS and Reproductive Health 
Survey (NARHS) carried out in 2007 and 2012 respectively. The NARHS is a cross-sectional household survey of individuals covering all the 36 states of Nigeria and the Federal Capital Territory (FCT) among men aged between 15 to 64 years and women of reproductive age group (15-49years). The main objective of the NARHS was to obtain accurate HIV prevalence estimates and current reproductive health behaviours along key programmes at the national, zonal and at state levels. A nationally representative sample was selected using a four-level multi-stage stratified cluster sampling procedure to select 6,161 males and 5,360 females in the 2007 survey while 15,596 males and 15,639 females living in households in rural and urban areas in Nigeria were selected in the 2012 survey. The households were selected from an updated master sampling frame of rural and urban localities developed and maintained by the National Population Commission ${ }^{7}$. This gave all eligible persons a known probability of selection. Data was collected from the respondents using a semi structured questionnaire by trained interviewers and supervisors who ensured quality of data collected. Only women of reproductive age group were extracted as database for this study. The main dependent variables of interest were (a) whether the woman had ever been pregnant, (b) at the time they became pregnant did they want the pregnancy and (c) were they using any form of contraceptives at this period. Independent variables include socio demographic characteristics of the women, knowledge of family planning methods, perception of men supporting family planning and fear of side effects of family planning. The unmet need for family planning was computed using the formula below ${ }^{4,5}$.

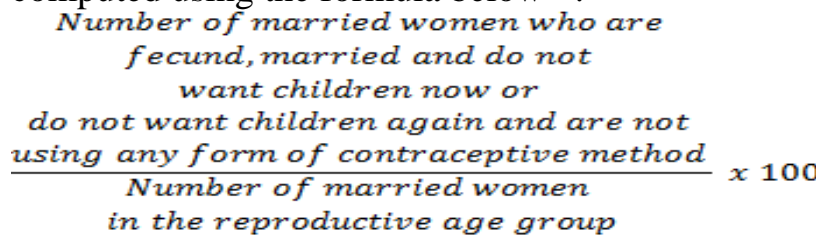

Data Analysis for this study was done at geopolitical and locality levels for all selected variables using SPSS version 20.0. Descriptive statistics was used to describe the socio demographic characteristics of the women of child bearing age. Chi-square test was used to investigate the significance of the association between unmet need for family planning and each independent variable. Independent predictors of unmet need were explored using binary logistic regression models. All tests were carried out at the $5 \%$ level of statistical significance. The Federal Ministry of Health of Nigeria has permitted researchers to re-analyse any component of the NARHS database for any intellectual information as done in this study.

\section{Results}

A total of 5,132 women of child bearing age (15$49 y$ rs) with mean age of $26.9 \pm 8.56$ years and 15,634 women with a mean age of $29.0 \pm 9.54$ years were extracted from the 2007 and 2012 survey respectively. Table 1 shows the socio demographic characteristics of the women of reproductive age group by urban and rural locations.

The highest proportion of women interviewed were aged between 15-24 years $(44.3 \%$ and $35.7 \%)$ respectively in both surveys and more than $60 \%$ were currently married (63.3\% and 66.3\%) in 2007 and 2012 respectively. Likewise, about a sixth of the women in both surveys (63\% and $63.2 \%$ ) had at least secondary education with preponderance in the urban areas. The proportion of Muslims and Christians was slightly different as there were a higher proportion of Muslims (50.2\%) in 2007 as compared to $41.7 \%$ in 2012 survey. However, most of the women interviewed in both surveys were from the northern part of the country $(56.5 \%$ and $53.3 \%)$ with those from the North West being in the highest proportion $(25.4 \%$ and $19.4 \%$ respectively).

Furthermore, about a third of the women interviewed in both surveys were unemployed including housewives while those involved in farming activities increased between 2007 and 2012 with a rural preponderance $(8.6 \%, 14.4 \%$ respectively).

\section{Contraceptive Use}

Majority of the women had never used any form of family planning method and this proportion increased from $77.8 \%$ in 2007 to $80.4 \%$ in 2012 with a higher proportion of them from the rural areas. Furthermore, just above sixty percent of the women who had ever used any form of family 
Table 1: Socio Demographic Characteristics of Women Within Reproductive Age Group by Urban and Rural Location (NARHS 2007-2012).

\begin{tabular}{|c|c|c|c|c|c|c|}
\hline & $\begin{array}{l}2007 \\
\text { URBAN } \\
(\mathbf{N}=1769) \\
n(\%) \\
\end{array}$ & $\begin{array}{l}\text { RURAL } \\
(\mathbf{N}=3363) \\
\text { n(\%) }\end{array}$ & $\begin{array}{l}\text { TOTAL } \\
(\mathrm{N}=5132) \\
\mathrm{n}(\%)\end{array}$ & $\begin{array}{l}2012 \\
\text { URBAN } \\
(N=4911) \\
n(\%)\end{array}$ & $\begin{array}{l}\text { RURAL } \\
(\mathrm{N}=10723) \\
\text { n(\%) }\end{array}$ & $\begin{array}{l}\text { TOTAL } \\
(\mathbf{N}=15634) \\
n(\%)\end{array}$ \\
\hline \multicolumn{7}{|l|}{ Age (Yrs) } \\
\hline $15-24$ & $769(43.5)$ & $1504(44.7)$ & $2273(44.3)$ & $1614(32.9)$ & $3967(37.0)$ & $5581(35.7)$ \\
\hline $25-34$ & $599(33.9)$ & $1078(32.1)$ & $1677(32.7)$ & $1792(36.5)$ & $3456(32.2)$ & $5248(33.6)$ \\
\hline $35-44$ & $360(20.4)$ & $669(19.9)$ & $1029(20.1)$ & $1043(21.2)$ & $2279(21.3)$ & $3322(21.2)$ \\
\hline $45-49$ & $41(2.3)$ & $112(3.3)$ & $153(3.0)$ & $462(9.42)$ & $1021(9.5)$ & $1483(9.5)$ \\
\hline \multicolumn{7}{|l|}{ Marital status } \\
\hline Currently married & $991(56.0)$ & $2258(67.1)$ & $3249(63.3)$ & $3063(62.4)$ & $7303(68.1)$ & $10366(66.3)$ \\
\hline $\begin{array}{l}\text { Living with a sexual } \\
\text { partner }\end{array}$ & $67(3.8)$ & $107(3.2)$ & $174(3.4)$ & $140(2.9)$ & $291(2.7)$ & $431(2.8)$ \\
\hline Never married & $640(36.2)$ & $819(24.4)$ & $1459(28.4)$ & $1438(29.3)$ & $2498(23.3)$ & $3936(25.2)$ \\
\hline Separated/Divorced & $39(2.2)$ & $74(2.2)$ & $113(2.2)$ & $138(2.8)$ & $263(2.5)$ & $401(2.6)$ \\
\hline Widowed & $32(1.8)$ & $105(3.1)$ & $137(2.7)$ & $132(2.7)$ & $368(3.4)$ & $500(3.2)$ \\
\hline \multicolumn{7}{|l|}{ Education } \\
\hline No formal Education & $324(18.3)$ & $1576(46.9)$ & $1900(37.0)$ & $942(19.2)$ & $4809(44.8)$ & $5751(36.8)$ \\
\hline Secondary and below & $1156(65.3)$ & $1662(49.4)$ & $2818(54.9)$ & $3036(61.8)$ & $5360(50.0)$ & $8396(53.7)$ \\
\hline Higher & $289(16.3)$ & $125(3.7)$ & $414(8.1)$ & $993(19.0)$ & $554(5.2)$ & $1487(9.5)$ \\
\hline \multicolumn{7}{|l|}{ Occupation } \\
\hline $\begin{array}{l}\text { Professional/Civil } \\
\text { Servant }\end{array}$ & $214(12.1)$ & $157(4.7)$ & $371(7.2)$ & $459(9.3)$ & $308(2.9)$ & $767(4.9)$ \\
\hline Self Employed_skilled & $500(28.3)$ & $752(22.4)$ & $1252(24.4)$ & $1571(32.0)$ & $1697(15.8)$ & $3268(20.9)$ \\
\hline Self & $111(6.3)$ & $223(6.6)$ & $334(6.5)$ & $484(9.9)$ & $642(6.0)$ & $1126(7.2)$ \\
\hline \multicolumn{7}{|l|}{ Employed_unskilled } \\
\hline Farming & $58(3.3)$ & $384(11.4)$ & $442(8.6)$ & $169(3.4)$ & $2088(19.5)$ & $2257(14.4)$ \\
\hline Student & $519(29.3)$ & $608(18.1)$ & $1127(22.0)$ & $1071(21.8)$ & $1665(15.5)$ & $2736(17.5)$ \\
\hline Unemployed & $367(20.7)$ & $1239(36.8)$ & $1606(31.3)$ & $1157(23.6)$ & $1323(40.3)$ & $5480(35.1)$ \\
\hline \multicolumn{7}{|l|}{ Religion } \\
\hline Islam & $780(44.1)$ & $1796(53.4)$ & $2576(50.2)$ & $2049(41.7)$ & $4472(41.7)$ & $6521(41.7)$ \\
\hline Christianity & $980(55.4)$ & $1543(45.9)$ & $2523(49.2)$ & $2830(57.6)$ & $6096(56.8)$ & $8926(57.1)$ \\
\hline Others & $9(0.5)$ & $24(0.7)$ & $33(0.6)$ & $32(0.7)$ & $155(1.4)$ & $187(1.2)$ \\
\hline \multicolumn{7}{|l|}{ Zone } \\
\hline North Central & $263(14.9)$ & $639(19.0)$ & $902(17.6)$ & $909(18.5)$ & 2043(19.1) & 2952(18.9) \\
\hline North East & $178(10.1)$ & $516(15.3)$ & $694(13.5)$ & $488(9.9)$ & $1860(17.3)$ & $2348(15.0)$ \\
\hline North West & $331(18.7)$ & $972(28.9)$ & $1303(25.4)$ & $649(13.2)$ & $2386(22.3)$ & $3035(19.4)$ \\
\hline South East & $224(12.7)$ & $376(11.2)$ & $600(11.7)$ & $317(6.5)$ & $1941(18.1)$ & $2258(14.4)$ \\
\hline South South & $244(13.8)$ & $521(15.5)$ & $765(14.9)$ & $663(13.5)$ & $1868(17.4)$ & $2531(16.2)$ \\
\hline South West & $529(29.9)$ & $339(10.1)$ & $868(16.9)$ & $1885(38.4)$ & $625(5.8)$ & $2510(16.1)$ \\
\hline
\end{tabular}

planning method are currently using a method with a slight urban preponderance in 2012( $\mathrm{p}<0.05)$ but no urban-rural differential in the 2007 survey. Most common form of family planning method used by these women were modern contraceptive methods(male condoms, IUDs, implants, OCPs, $71.6 \%$ and $77 \%$ ) as compared to traditional methods (natural, rhythm and abstinence method, $28.4 \%$ and23\%) in the 2007 and 2012 survey respectively. The use of modern contraceptive methods increased over the 5 year study period with the condoms $(58.8 \%, 58.9 \%)$ remaining the most common form of modern method used, although with an urban preponderance.

\section{Prevalence and patterns of unmet needs for family planning}

The total unmet need for family planning was found to be $9.1 \%$ in 2007 and this increased to $11.4 \%$ in 2012 survey. There was a higher preponderance in the urban areas as compared to the rural areas which was found to be statistically significant in 2007 survey but however was not statistically significant in $2012(\mathrm{p}=0.03, \mathrm{p}=0.08$ respectively) (See Figure. 1). On socio demographic determinants of unmet need for family planning, there was no association between the age distribution, religion, education and 
Figure 1: Prevalence of Unmet Need for Family Planning by Location and Year of Survey.

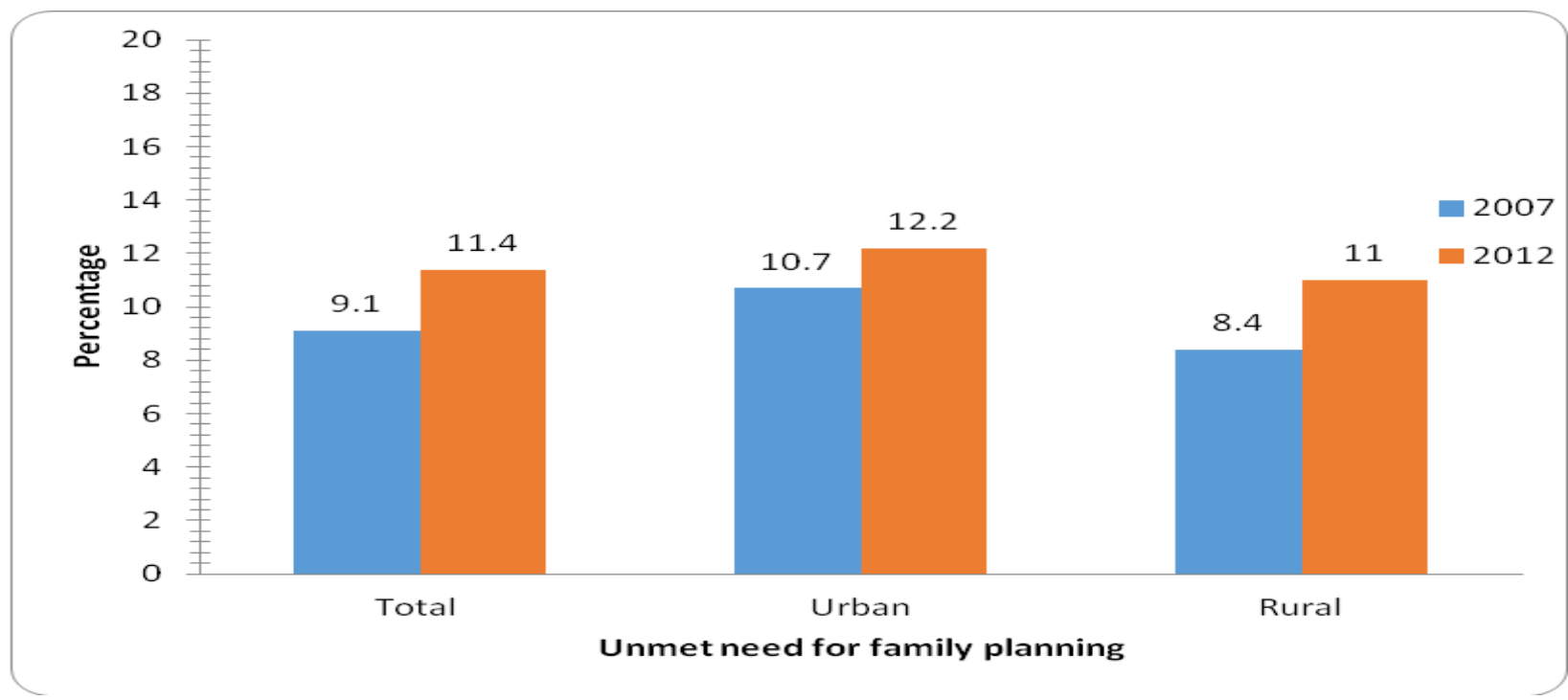

occupation, although unmet need was found to be highest among students (18.5\%) in the 2007 survey. ( $p>0.05)$. Furthermore, urban dwellers were found to have a higher percentage of unmet need for family planning over the five year period. Respondents in the North Western part of the country had a higher proportion $(32.3 \%$ and $24.7 \%$ ) of women with unmet need for family planning in the Northern region and this was consistent over the five year period. In the southern region, women in the South western(12.\%) zone had the highest proportion in 2007 survey while the South South $(17.6 \%)$ had the highest proportion of women with unmet need for family planning by 2012. Nevertheless, location $(\mathrm{p}=0.034)$ and zone $(\mathrm{p}=0.00)$ were found to be statistically significantly associated with unmet need for family planning in 2007 while only location was significant in 2012(p=0.000). In addition, women who had discussed family planning method with their spouses and did not fear any side effects of modern family planning had a lower proportion with unmet need, however only fear of side effects was found to be statistically significant in the 2012 survey $(\mathrm{p}<0.05)$. From the 2012 survey, women aged 35-44yrs (OR: 1.3, 95\%CI: 1.0-15) and feared side effects of family planning methods (OR:1.3,95\%CI:1.1-1.6) were about 2 times more likely to have an unmet need for family planning. Whilst in the 2007 survey, students were 3 times more likely to have an unmet need for family planning (OR: 2.7, 95\% CI: 1.2-6.0).

In addition, rural dwellers were about 2 times less likely to have unmet needs for family planning methods, though this did not change between 2007 (OR: 0.7, 95\% CI: 0.6-0.9) and 2012(OR: 0.8, 95\% CI: 0.6-0.9) respectively.

\section{Discussion}

Unmet needs for family planning has remained a major indicator for monitoring the progress towards reduction of maternal mortality worldwide. Findings from this study revealed an overall prevalence of total unmet need for family planning to be $9.1 \%$ and $11.4 \%$ over the five year period. These values are lower compared to the $20.2 \%$ and $16 \%$ reported in the 2008 and 2013 NDHS respectively and in contrast to the increasing pattern ${ }^{6,7}$. This could be due to selection of study population and the primary objective of these surveys. But the finding of $9.1 \%$ in 2007 was similar to a study carried out in Botswana using demographic health data of $2007 .^{23}$ This shows that the reported global prevalence of unmet needs in these study locations might have been overestimated probably due to denominators used in calculation.

Furthermore, older women were more likely to have unmet need probably due to confidence gained with previous experiences of pregnancy 
Table 2: The Relationship Between Demographic Characteristics and Need for Family Planning Among Women of Reproductive Age Group in Nigeria (2007-2012).

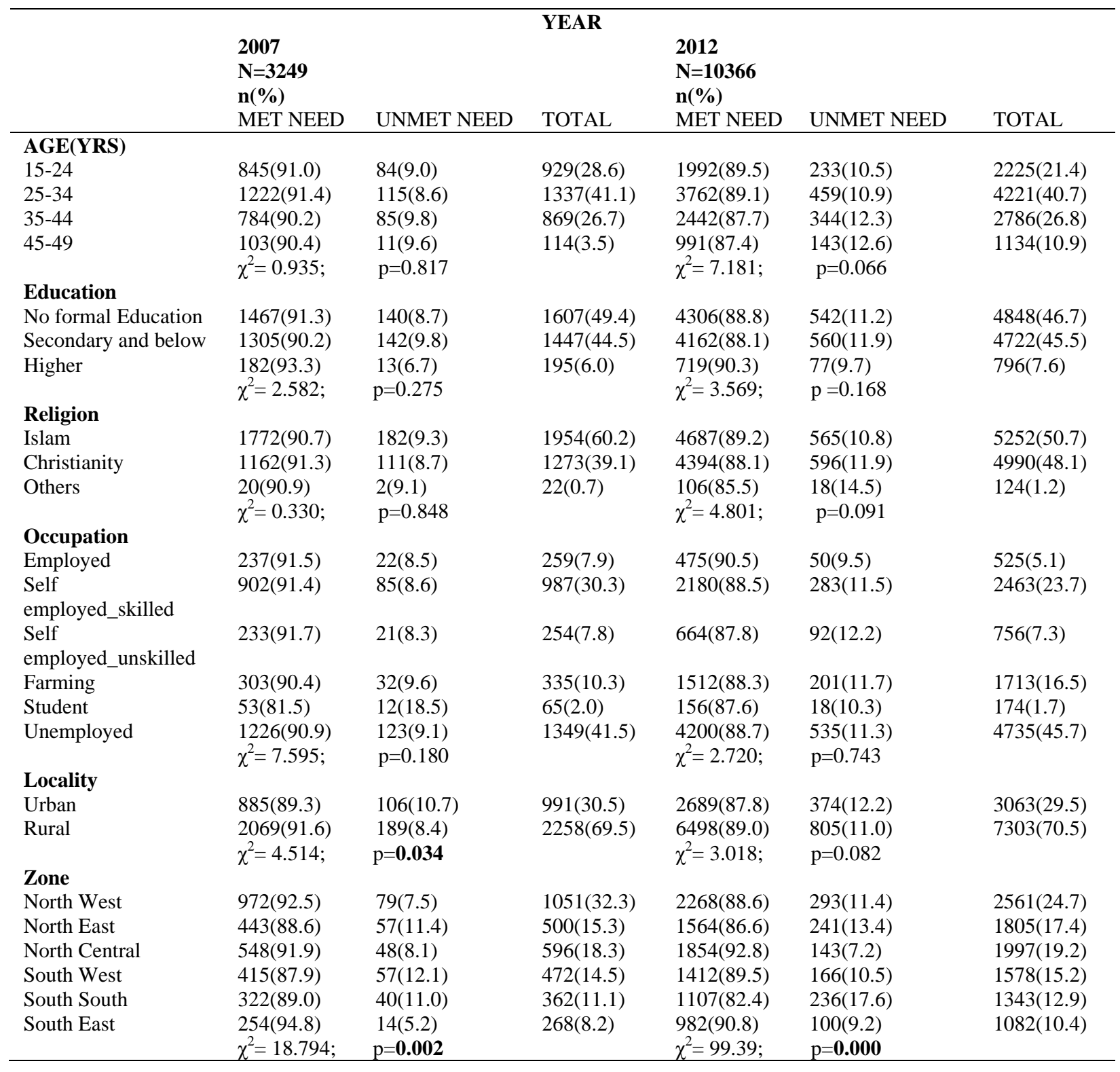

Table 3: The Relationship Between Selected Characteristics and Need For Family Planning (FP) Among Married Women of Reproductive Age Group in Nigeria.

\begin{tabular}{|c|c|c|c|c|}
\hline & $\begin{array}{l}\text { Year } \\
\mathbf{2 0 0 7} \\
\mathbf{N}=\mathbf{3 2 4 9} \\
\mathbf{n}(\%) \\
\text { MET NEED }\end{array}$ & UNMET NEED & $\begin{array}{l}2012 \\
\mathbf{N}=\mathbf{1 0 3 6 6} \\
\mathbf{n}(\%) \\
\text { MET NEED }\end{array}$ & UNMET NEED \\
\hline \multicolumn{5}{|l|}{$\begin{array}{l}\text { Know where to obtain FP } \\
\text { method }\end{array}$} \\
\hline Yes & $1538(91.1)$ & $150(8.8)$ & $4352(88.9)$ & $546(11.1)$ \\
\hline No & $1416(90.7)$ & $145(9.3)$ & $4835(88.4)$ & $633(11.6)$ \\
\hline Fear of side effect of any & $\chi^{2}=0.153$ & $\mathrm{p}=0.690$ & $\chi^{2}=0.471$ & $\mathrm{p}=0.492$ \\
\hline
\end{tabular}




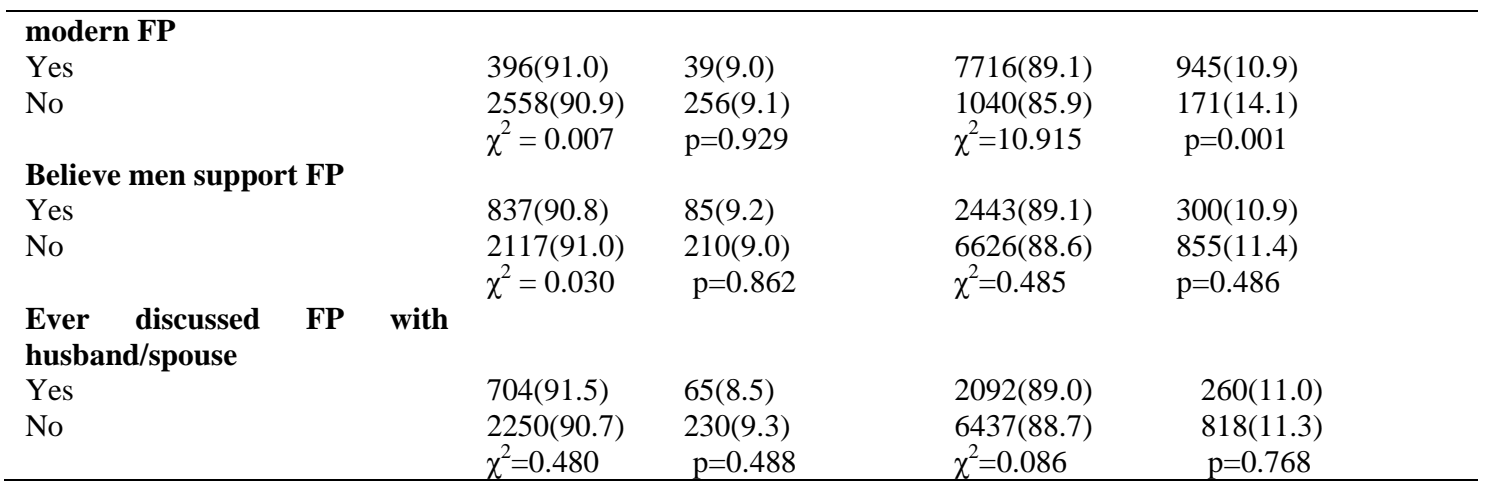

Table 4: Independent Predictors Of Unmet Need for Family Among Women of Reproductive Age in Nigeria (NARHS, 2007-2012).

\begin{tabular}{|c|c|c|c|c|c|c|c|c|}
\hline \multirow[t]{2}{*}{ Selected Characteristics } & \multicolumn{4}{|l|}{2007} & \multicolumn{4}{|l|}{2012} \\
\hline & $\beta$ & OR & p-value & $95 \% \mathrm{CI}$ & B & OR & p-value & $95 \% \mathrm{CI}$ \\
\hline \multicolumn{9}{|l|}{ Age group } \\
\hline $15-24$ & 1 & & & & 1 & & & \\
\hline $25-34$ & 0.0 & 1.0 & 0.946 & $0.7-1.4$ & 0.66 & 1.0 & 0.508 & $0.9-1.3$ \\
\hline $35-44$ & 1.0 & 1.1 & 0.317 & $0.8-1.7$ & 2.20 & 1.3 & 0.028 & $1.0-1.5$ \\
\hline $45-49$ & 0.5 & 1.2 & 0.575 & $0.6-2.4$ & 1.65 & 1.2 & 0.099 & $0.9-1.6$ \\
\hline \multicolumn{9}{|l|}{ Education } \\
\hline Primary & 1 & & & & 1 & & & \\
\hline Secondary and below & 0.6 & 1.1 & 0.517 & $0.8-1.5$ & 0.89 & 0.9 & 0.895 & $0.8-1.2$ \\
\hline Higher & -1.3 & 0.6 & 0.183 & $0.3-1.2$ & 0.29 & 0.8 & 0.286 & $0.6-1.6$ \\
\hline \multicolumn{9}{|l|}{ Religion } \\
\hline Islam & 1 & & & & 1 & & & \\
\hline Christianity & -1.5 & 0.7 & 0.128 & $0.5-1.1$ & 1.8 & 1.1 & 0.064 & $0.9-1.5$ \\
\hline Traditional/Others & -0.4 & 0.7 & 0.675 & $0.2-3.2$ & 1.5 & 1.6 & 0.138 & $0.8-2.8$ \\
\hline \multicolumn{9}{|l|}{ Occupation } \\
\hline Government Employed & 1 & & & & 1 & & & \\
\hline Self Employed_Skilled & -0.5 & 0.9 & 0.595 & $0.5-1.5$ & 0.6 & 1.1 & 0.528 & $0.7-1.6$ \\
\hline Self Employed_Unskilled & -0.6 & 0.8 & 0.577 & $0.4-1.6$ & 1.3 & 1.3 & 0.193 & $0.8-2.0$ \\
\hline Farming & 0.5 & 1.2 & 0.619 & $0.6-2.1$ & 0.7 & 1.1 & 0.441 & $0.7-1.7$ \\
\hline Student & 2.5 & 2.7 & 0.013 & $1.2-6.0$ & 1.2 & 1.5 & 0.201 & $0.8-2.8$ \\
\hline Unemployed & 0.1 & 1.0 & 0.933 & $0.6-1.7$ & 0.9 & 1.2 & 0.334 & $0.8-1.8$ \\
\hline \multicolumn{9}{|l|}{ Location } \\
\hline Urban & 1 & & & & 1 & & & \\
\hline Rural & -2.1 & 0.7 & 0.034 & $0.6-0.9$ & -2.9 & 0.8 & 0.004 & $0.6-0.9$ \\
\hline \multicolumn{9}{|l|}{ Zone } \\
\hline North Central & 1 & & & & 1 & & & \\
\hline North East & 1.4 & 1.3 & 0.163 & $0.8-2.0$ & 6.9 & 2.4 & 0.000 & $1.8-3.0$ \\
\hline North West & -0.8 & 0.8 & 0.422 & $0.6-1.2$ & 5.4 & 2.0 & 0.000 & $1.5-2.6$ \\
\hline South East & -1.0 & 0.7 & 0.303 & $0.4-1.4$ & 2.4 & 1.4 & 0.014 & $1.0-1.9$ \\
\hline South South & 1.8 & 1.5 & 0.069 & $0.9-2.6$ & 8.0 & 2.8 & 0.000 & $2.2-3.7$ \\
\hline South West & 2.1 & 1.6 & 0.030 & $1.0-2.5$ & 2.7 & 1.4 & 0.007 & $1.1-1.9$ \\
\hline \multicolumn{9}{|l|}{ Know where to obtain FP } \\
\hline Yes & 1 & & & & 1 & & & \\
\hline No & 0.8 & 1.1 & 0.378 & $0.8-1.5$ & 1.8 & 1.1 & 0.070 & $0.9-1.3$ \\
\hline \multicolumn{9}{|l|}{ Fear Side effect of FP } \\
\hline Yes & 1 & & & & 1 & & & \\
\hline No & 0.2 & 1.0 & 0.843 & $0.7-1.5$ & 2.7 & 1.3 & 0.006 & $1.1-1.6$ \\
\hline \multicolumn{9}{|l|}{ Men Support FP } \\
\hline Yes & 1 & & & & 1 & & & \\
\hline No & 0.3 & 1.0 & 0.778 & $0.8-1.4$ & 0.3 & 1.0 & 0.792 & $0.8-1.2$ \\
\hline \multicolumn{9}{|l|}{ Discussed FP with spouse } \\
\hline Yes & 1 & & & & 1 & & & \\
\hline No & 0.7 & 1.1 & 0.472 & $0.8-1.5$ & 0.4 & 1.0 & 0.683 & $0.0-0.1$ \\
\hline
\end{tabular}


and child birth.

This is however, is in line with most studies done in Nigeria as well as other sub-Saharan countries $^{2,9,12,13}$. Interestingly, the northern part of the country has been identified as having lesser prevalence of unmet need and this is in consonance with the demographic health survey. However, in the southern part, there has been a change in the unmet needs from the South West to the South South, this could probably be due to the improved education and westernized life styles in South Western Nigeria. This was also similar to some studies done in Uganda which reported regional differences ${ }^{12,24}$.

The marginal difference in the prevalence of unmet need in the urban and rural areas as observed might be due to the industrialization and busy schedules in the urban cities which is in consonance with other studies in Sub Saharan Africa $^{24,25,26}$.

\section{Conclusion}

Unmet need for family planning has increased over the five year period. It is marginally higher in urban areas and southern part of Nigeria. Fear of side effects of family planning methods and increasing age were major barriers which changed over the five year period. A combination of adequate family planning information during antenatal care for the pregnancy of first born child and encouraging the presence of the spouse or other relatives at least once during the antenatal visits may further help reduce unmet need for family planning.

\section{References}

1. WHO, Safe Abortion: Technical and Policy Guidance for Health Systems, World Health Organization, Geneva, Switzerland, 2nd edition, 2012,http:// apps.who.int/iris/bitstream/10665/70914/1/9789241 548434_eng.pdf.

2. Monjok E, Smesny A, Ekabua JE et al: Contraceptive practices in Nigeria: Literature review and recommendation for future policy decisions: Open Access Journal of Contraception 2010:1:9-22.

3. World Health Organization, May 2011: Fact Sheet: www.who.int/mediacenter/factsheets/fs348/en/inde x.htm.Accessed, June 2011.
4. Westoff Charles F. Unmet Need at the End of the Century: DHS Comparative Reports No.1. Calverton, Maryland: ORC Macro; 2001.

5. Westoff, Charles F. 2006. New Estimates of Unmet Need and the Demand for Family Planning. DHS Comparative Reports No. 14. Calverton, Maryland, USA. Macro International Inc.

6. Nigerian Demography Health Survey Report. 2013.

7. Nigerian Demography Health Survey Report. 2008.

8. National Population Commission (NPC) [Nigeria] and ORC Macro. 2004. Nigeria Demographic and Health Survey 2003. Calverton, Maryland: National Population Commission and ORC Macro.

9. Health 2011: Maternal and Reproductive Health Issues. www.cdc.org/reproductivehealth/index.htm. Accessed May 2011.

10. Igwegbe AO, Ugboaja JO, Monago EN: Prevalence and determinants of unmet need for family planning in Nnewi, South East Nigeria: Int. Journal of Med and Med Sci. 2009: 1(8): 325-329.

11. Srivastava DK, Goutam P, Goutam R, Gour N, Bansal M : A study to assess the unmet need of family planning in Gwalior district and to study the factors that helps in determining it. National Journal of Community Medicine. 2011; 2(1): 28-31.

12. Khan, Shane, Sarah E.K. Bradley, Joy Fishel, and Vinod Mishra. 2008. Unmet Need and the Demand for Family Planning in Uganda: Further Analysis of the Uganda Demographic and Health Surveys, 19952006. Calverton, Maryland, USA: Macro International Inc.

13. Abdel Aziem A, Duria A Rayis, Mona Mamoune: Use of family planning methods in Kassala, Eastern Sudan: BMC Res Notes. 2011:4(43).

14. Adetokunbo T, Oluwarotimi A, Abiola et al: Contraceptive knowledge and usage amongst female secondary school students in Lagos, South West Nigeria: Journal of Public Health and Epidemiology 2011: 3(1):34-37.

15. Alan Guttmacher Institute. International Family Planning Perspectives; Fertility Transition. New York: University of North Carolina; 2004.

16. Bongrats, J. and Bruce, J.: The causes of unmet need for contraception and the social content of services, Studies in Family Planning. 1995: 26(2), 57-75.

17. Casterline, JB and Sinding, SW: Unmet need for family planning in developing countries and implications for population policy. Popul and Dev. Review. 2000; 26: 691-723.

18. Center for Communication Programmes. Population Reports. Johns Hopkins Bloomberg School of Public Health: Baltimore; 2003: 3-30.

19. Nazzar A., Adongo Philip B., Binka Fred N. et al. Developing a culturally appropriate Family planning program for the Navrongo Experiment; Studies in Family planning. New York: Population Council. 1995;.26( 6).

20. Phillips James F., Hossain Bazle M., Kuenning Arends 
M., The Long-term Demographic Role of Community-based Family Planning in Rural Bangladesh; Studies in Family Planning. New York: Population Council. 1996; 27( 4): 204-219

21. Prata N: The need for family planning. Popul Environ .2007; 28:212-222.

22. Subhash B: Socio-economic and Demographic Determinants of Unmet Need for Family Planning in India and its Consequences. Research on Humanities and Social Sciences . 2013; 3(3):22222863.

23. Letamo, G. and K. Navaneetham (2015). "Levels, trends and reasons for unmet need for family planning among married women in Botswana: a crosssectional study." BMJ Open 5(3): e006603.

24. Vohra R, Vohra A, Sharma S, Rathore MS, Sharma BN, Sharma MP : Determinants of the unmet need for family among women of Jaipur, Rajasthan. Int J Adv Med Res. 2014; 1:20-5.

25. Kisaakye, P. (2013). "Determinants of unmet need for contraception to space and limit births among various groups of currently married women in Uganda." European Scientific Journal.

26. Ajong, A. B., et al. (2016). "Determinants of unmet need for family planning among women in Urban Cameroon: a cross sectional survey in the BiyemAssi Health District, Yaoundé." BMC women's health 16(1): 1 .

27. Oginni, A. B., et al. (2015). "Trend and Determinants of Unmet Need for Family Planning Services among Currently Married Women and Sexually Active Unmarried Women Aged 15-49 in Nigeria (2003-2013)." Etude de la Population Africaine 29(1): 1483.

28. Adebowale, S. A. and M. E. Palamuleni (2014). "Determinants of unmet need for modern contraception and reasons for non-use among married women in rural areas of Burkina Faso." Etude de la Population Africaine 28(1): 499. 